\title{
Tracing anthropogenic radiocarbon transfer through the tropical north Atlantic using deep sea bamboo corals
}

\author{
QIAN LIU ${ }^{1}$, LAURA F. ROBINSON ${ }^{1}$, ERICA HENDY ${ }^{1}$, \\ JOSEPH STEWART ${ }^{1}$, TIMOTHY KNOWLES ${ }^{1}$, TAO LI ${ }^{2}$ AND \\ ANA SAMPERIZ ${ }^{3}$ \\ ${ }^{1}$ University of Bristol \\ ${ }^{2}$ Nanjing University \\ ${ }^{3}$ Cardiff University \\ Presenting Author: qian.liu@bristol.ac.uk
}

Nuclear tests conducted during 1950s and 1960s provided a useful anthropogenic tracer, bomb radiocarbon, to reconstruct ocean ventilation over the recent past. With sparse historical radiocarbon observation, especially in the deep ocean, continuous high-resolution records are needed to fill the time gap. Long lived deep-sea bamboo corals serve as a potential archive with their robust calcium carbonate bamboo-like skeleton.

Four deep-sea bamboo corals were collected between $1400 \mathrm{~m}$ and $2000 \mathrm{~m}$ water depth in the central and eastern equatorial Atlantic in 2013, currently situated in North Atlantic Deep Water (NADW), to reconstruct the ventilation history over the last century. The distinct characteristic of bamboo coral skeletons, which have a jointed axis consisting of organic nodes and calcium carbonate internodes, allows us to generate continuous, high-resolution radiocarbon records for both the surface and deep ocean. The bomb radiocarbon maximum recorded in organic nodes is lower and later than the maxima recorded in shallow water corals and model outputs suggesting that the organic node combines surface and subsurface photic zone radiocarbon. By contrast, the radiocarbon content in calcitic internodes documents the radiocarbon signature of ambient seawater. Combined with previous records from the northwest Atlantic, we reconstruct the time scales of bomb radiocarbon transport from the north Atlantic to the coral sites in central and eastern equatorial Atlantic. 